\title{
Restricted spirometry and cardiometabolic comorbidities: results from the international population based BOLD study
}

Katarzyna Kulbacka-Ortiz ${ }^{1,2 \dagger}$, Filip J. J. Triest ${ }^{3,4,5 \dagger}{ }^{\dagger}$, Frits M. E. Franssen ${ }^{3,5}$, Emiel F. M. Wouters ${ }^{3,5,11}$, Michael Studnicka ${ }^{6}$, William M. Vollmer ${ }^{7}$, Bernd Lamprecht ${ }^{8,9}$, Peter G. J. Burney ${ }^{10}$, Andre F. S. Amaral ${ }^{10}$ and Lowie E. G. W. Vanfleteren ${ }^{1,2^{*}}$ (D)

\begin{abstract}
Background: Whether restricted spirometry, i.e. low Forced Vital Capacity (FVC), predicts chronic cardiometabolic disease is not definitely known. In this international population-based study, we assessed the relationship between restricted spirometry and cardiometabolic comorbidities.
\end{abstract}

Methods: A total of 23,623 subjects (47.5\% males, $19.0 \%$ current smokers, age: $55.1 \pm 10.8$ years) from five continents (33 sites in 29 countries) participating in the Burden of Obstructive Lung Disease (BOLD) study were included. Restricted spirometry was defined as post-bronchodilator $\mathrm{FVC}<5$ th percentile of reference values. Self-reports of physician-diagnosed cardiovascular disease (CVD; heart disease or stroke), hypertension, and diabetes were obtained through questionnaires.

Results: Overall 31.7\% of participants had restricted spirometry. However, prevalence of restricted spirometry varied approximately ten-fold, and was lowest (8.5\%) in Vancouver (Canada) and highest in Sri Lanka (81.3\%). Crude odds ratios for the association with restricted spirometry were 1.60 (95\% Cl 1.37-1.86) for CVD, 1.53 (95\% Cl 1.40-1.66) for hypertension, and 1.98 (95\% Cl 1.71-2.29) for diabetes. After adjustment for age, sex, education, Body Mass Index (BMI) and smoking, the odds ratios were 1.54 (95\% Cl 1.33-1.79) for CVD, 1.50 (95\% Cl 1.39-1.63) for hypertension, and 1.86 (95\% Cl 1.59-2.17) for diabetes.

Conclusion: In this population-based, international, multi-site study, restricted spirometry associates with cardiometabolic diseases. The magnitude of these associations appears unattenuated when cardiometabolic risk factors are taken into account.

Keywords: Restricted spirometry, Lung function impairment, Cardiovascular disease, Hypertension, Diabetes, Comorbidity

*Correspondence: Lowie.vanfleteren@gu.se

${ }^{\dagger}$ Katarzyna Kulbacka-Ortiz and Filip J. J. Triest contributed equally to the manuscript and are co-first authors

${ }^{1}$ COPD Center, Department of Respiratory Medicine and Allergology, Sahlgrenska University Hospital, Gothenburg, Sweden

Full list of author information is available at the end of the article

\section{Background}

Restrictive lung function is defined as reduced lung expansion expressed as a decreased total lung capacity. It may reflect several underlying conditions and diseases, such as interstitial lung diseases, pleural effusions and disorders, thoracic deformities, neuromuscular diseases, diaphragmatic disorders, obesity, heart failure, pregnancy and pain [1]. Dynamic spirometry has limitations 
in identifying restrictive lung diseases [2], but it can effectively exclude a restrictive disease when forced vital capacity (FVC) is normal. Further, restricted spirometry is clinically relevant as it is prevalent and associated with impaired quality of life and increased mortality [2-6].

Restricted spirometry has been associated with being female, elderly, heavy smoker, underweight or obese, and manual worker in industry [3, 7-9]. A history of tuberculosis, particularly in low- and middle-income countries where this is common is an additional risk factor $[10,11]$. Several North American and European studies have reported an association of restrictive lung function with heart disease, hypertension, and diabetes [12-16]. Low FVC has also been associated with markers of cardiometabolic disease [17-20]. In addition, it has been recently shown that reduced lung function (defined as forced expiratory volume in the first second $\left(\mathrm{FEV}_{1}\right)$ below $80 \%$ of predicted) in early adulthood is associated with a higher and earlier incidence of respiratory, cardiovascular and metabolic comorbidities later in life [21].

Within the Burden of Obstructive Lung Disease (BOLD) study, an international population-based study covering a great number of countries with different ethnic, economic and socio-cultural backgrounds, we investigated the association between the presence of restricted spirometry and the presence of self-reported physiciandiagnosed cardiovascular (CVD), hypertension and diabetes, taking into account risk factors like age, sex, education, smoking and body mass index (BMI). In addition, we stratified the results for high- and low-/middleincome countries.

\section{Methods}

\section{Study design and participants}

The design and rationale for the BOLD initiative have been previously published [22]. A random sample population strategy was used for recruitment of participants from all study sites. In total, 33 sites (Table 1) completed data collection and were included in this analysis. Each participating site aimed to recruit a sample of at least 300 men and 300 women who were not institutionalized, were aged $\geq 40$ years, and were living in a well-defined administrative area in which the total population exceeded 150,000. Participants were interviewed by means of a questionnaire and underwent a standardized assessment. Approval was obtained from each local ethics committee, and written informed consent was obtained from each participant. Participants between 40 to 89 years, with a usable postbronchodilator lung function and smoking history were extracted from the BOLD database. Those with complete data on subject characteristics, comorbidities and lung function were selected for this study.

\section{Assessments}

Questionnaire

Questionnaire data was obtained by face-to-face interviews conducted by trained and certified staff in the participant's native language. All participants completed a core questionnaire, based on standardised instruments, which included information on risk factors for lung disease and comorbidities [22]. A dichotomous question for self-reported physician-diagnosed comorbidities, such as heart disease, stroke, hypertension or diabetes was used. For example: "Has a doctor or other health care provider ever told you that you had heart disease?" In this analysis, CVD refers to the presence of either heart disease or stroke.

\section{Spirometry}

Lung function data were collected using the ndd EasyOne Spirometer (ndd Medical Technologies, Zurich, Switzerland) [23]. Lung function was measured before and $15 \mathrm{~min}$ after administration of $200 \mu \mathrm{g}$ of salbutamol, administered with a metered dose inhaler with volume spacer. Local spirometry technicians were trained and certified. All spirograms were reviewed centrally based on standardised criteria [24]. Restrictive lung function was defined according to the lower limit of normal ( $<5$ th percentile) of the reference values for post-bronchodilator FVC [25]. The Third National Health and Nutrition Examination Survey (NHANES III) equations were used [26].

\section{Anthropometry}

Body height was measured to the nearest $0.5 \mathrm{~cm}$. Body weight was assessed to the nearest $0.1 \mathrm{~kg}$ after emptying the bladder and with the participants standing barefoot and wearing light indoor clothing. BMI was calculated as body weight/height ${ }^{2}\left(\mathrm{~kg} / \mathrm{m}^{2}\right)$.

\section{Statistical analysis}

Statistics were performed in Stata, version 13.1 (Stata Corporation, College Station, TX, USA). The relation between the presence of comorbidities and restrictive lung function, and six other covariates (i.e. known cardiovascular risk factors: sex [27], education (highest level of schooling completed: less than high school, high school, some college) [28], BMI $(\leq 18,18-25$, $\left.25-30,>30 \mathrm{~kg} / \mathrm{m}^{2}\right)$ [29], age $(40-49,50-59,60-69$, 70-89 years) [27], smoking status (never, former, current), and accumulated cigarette pack-years (0, 0-10, 10-20, 20-30, > 30)) [30] was analyzed with use of multivariable logistic regression analysis for each site. All regression models were adjusted for sampling weights within each site. 
Table 1 General characteristics of study participants at each site and overall

\begin{tabular}{|c|c|c|c|c|c|c|c|c|c|c|c|c|}
\hline \multirow[t]{2}{*}{ Site, Country } & \multirow[t]{2}{*}{$\mathrm{N}$} & \multicolumn{3}{|c|}{ Smoking status (\%) } & \multirow{2}{*}{$\begin{array}{l}\text { Sex male } \\
(\%)\end{array}$} & \multirow{2}{*}{$\frac{\text { Age (years) }}{\text { Mean } \pm S D}$} & \multirow{2}{*}{$\frac{\mathrm{BMI}\left(\mathrm{kg} / \mathrm{m}^{2}\right)}{\text { Mean } \pm \mathrm{SD}}$} & \multirow[t]{2}{*}{ RS (\%) } & \multicolumn{3}{|c|}{ Comorbidities (\%) } & \multirow{2}{*}{$\begin{array}{l}\text { GNI } \\
\text { High }\end{array}$} \\
\hline & & Current & Ex & Never & & & & & CVD & Hypertension & Diabetes & \\
\hline Adana, Turkey & 806 & 34.9 & 19.9 & 45.3 & 48.3 & $53.6 \pm 10.4$ & $29.6 \pm 5.3$ & 14.5 & 11.8 & 27.0 & 10.3 & No \\
\hline Annaba, Algeria & 862 & 16.7 & 21.9 & 61.4 & 49.8 & $52.9 \pm 9.7$ & $28.3 \pm 5.7$ & 26.8 & 6.6 & 22.2 & 14.4 & No \\
\hline Bergen, Norway & 656 & 26.2 & 36.6 & 37.2 & 49.2 & $59.7 \pm 12.5$ & $26.5 \pm 4.3$ & 9.3 & 15.4 & 29.4 & 5.9 & Yes \\
\hline Blantyre, Malawi & 399 & 3.8 & 9.3 & 87.0 & 39.8 & $52.2 \pm 9.7$ & $25.1 \pm 5.4$ & 47.6 & 2.5 & 20.1 & 6.0 & No \\
\hline CapeTown, SouthAfrica & 833 & 46.3 & 21.4 & 32.3 & 37.0 & $54.0 \pm 10.2$ & $27.9 \pm 7.4$ & 46.5 & 13.3 & 38.9 & 13.2 & No \\
\hline Chui, Kyrgyztan & 858 & 19.8 & 9.7 & 70.5 & 31.5 & $53.0 \pm 8.8$ & $28.5 \pm 5.6$ & 12.5 & 16.6 & 29.7 & 5.7 & No \\
\hline Colombo, Srilanka & 1020 & 12.9 & 7.5 & 79.6 & 44.6 & $53.7 \pm 9.4$ & $24.2 \pm 4.6$ & 81.3 & 5.9 & 20.6 & 13.4 & No \\
\hline Cotonou, Benin & 677 & 1.8 & 0.1 & 98.1 & 43.9 & $51.5 \pm 9.3$ & $26.4 \pm 5.5$ & 78.4 & 5.3 & 29.8 & 2.5 & No \\
\hline Fes, Morocco & 758 & 8.6 & 18.7 & 72.7 & 46.0 & $55.2 \pm 10.0$ & $27.9 \pm 5.3$ & 20.2 & 5.8 & 33.1 & 14.6 & No \\
\hline Guangzhou, China & 471 & 29.9 & 14.0 & 56.1 & 49.9 & $54.0 \pm 10.6$ & $23.3 \pm 3.3$ & 30.1 & 9.8 & 17.6 & 4.0 & No \\
\hline Hannover, Germany & 681 & 20.7 & 39.4 & 39.9 & 51.2 & $58.0 \pm 10.9$ & $27.3 \pm 4.6$ & 9.3 & 17.0 & 38.3 & 6.3 & Yes \\
\hline Ife, Nigeria & 859 & 2.6 & 7.9 & 89.5 & 39.1 & $55.5 \pm 11.5$ & $25.4 \pm 5.4$ & 70.7 & 0.2 & 2.3 & 0.8 & No \\
\hline Krakow, Poland & 522 & 29.3 & 32.4 & 38.3 & 50.8 & $55.6 \pm 11.4$ & $27.7 \pm 4.7$ & 10.2 & 32.4 & 42.0 & 11.1 & Yes \\
\hline Lexington, USA & 505 & 26.5 & 33.9 & 39.6 & 40.4 & $56.5 \pm 9.8$ & $30.8 \pm 6.8$ & 26.5 & 29.3 & 49.1 & 17.4 & Yes \\
\hline Lisbon, Portugal & 709 & 13.3 & 26.8 & 59.9 & 46.7 & $63.3 \pm 11.3$ & $28.2 \pm 4.7$ & 10.2 & 17.5 & 37.5 & 11.0 & Yes \\
\hline London, England & 672 & 21.0 & 41.2 & 37.8 & 48.1 & $58.0 \pm 11.4$ & $27.1 \pm 5.0$ & 16.8 & 7.1 & 33.0 & 6.5 & Yes \\
\hline Maastricht, Netherlands & 589 & 22.9 & 42.4 & 34.6 & 50.8 & $57.5 \pm 10.6$ & $27.4 \pm 4.5$ & 10.0 & 17.0 & 29.5 & 7.3 & Yes \\
\hline Manila, Philippines & 890 & 32.7 & 20.2 & 47.1 & 42.2 & $52.2 \pm 10.1$ & $24.9 \pm 4.7$ & 64.2 & 11.0 & 26.5 & 6.0 & No \\
\hline Mumbai, India & 440 & 6.6 & 3.2 & 90.2 & 62.5 & $51.1 \pm 8.9$ & $23.8 \pm 4.0$ & 69.8 & 2.3 & 10.0 & 5.2 & No \\
\hline NampicuanTalugtugPhilippines & 722 & 35.9 & 16.8 & 47.4 & 49.3 & $54.1 \pm 10.5$ & $21.5 \pm 3.9$ & 58.3 & 8.3 & 19.7 & 2.6 & No \\
\hline Naryn, Kyrgyztan & 816 & 15.1 & 9.8 & 75.1 & 38.5 & $53.2 \pm 9.7$ & $27.0 \pm 5.0$ & 9.8 & 11.6 & 15.7 & 1.0 & No \\
\hline Penang, Malaysia & 646 & 20.3 & 5.0 & 74.8 & 50.9 & $54.8 \pm 9.3$ & $26.0 \pm 4.5$ & 58.2 & 2.8 & 25.2 & 14.4 & No \\
\hline Pune, India & 843 & 8.9 & 3.0 & 88.1 & 59.4 & $52.4 \pm 9.8$ & $22.1 \pm 3.8$ & 66.3 & 1.4 & 5.1 & 2.1 & No \\
\hline Reykjavik, Iceland & 755 & 18.4 & 42.5 & 39.1 & 53.1 & $56.3 \pm 11.6$ & $27.9 \pm 4.9$ & 12.7 & 15.4 & 32.1 & 4.8 & Yes \\
\hline Riyadh, Saudi Arabia & 654 & 7.8 & 17.0 & 75.2 & 54.9 & $50.5 \pm 7.5$ & $31.2 \pm 6.0$ & 52.1 & 6.7 & 26.6 & 29.4 & Yes \\
\hline Salzburg, Austria & 1255 & 19.3 & 33.5 & 47.2 & 54.3 & $57.6 \pm 11.3$ & $26.4 \pm 4.2$ & 9.3 & 12.5 & 28.9 & 6.4 & Yes \\
\hline Sousse, Tunisia & 658 & 26.7 & 13.2 & 60.0 & 47.0 & $53.0 \pm 9.0$ & $29.3 \pm 5.6$ & 26.9 & 5.6 & 21.0 & 10.9 & No \\
\hline Srinagar, India & 739 & 10.3 & 1.9 & 87.8 & 54.9 & $51.7 \pm 10.3$ & $22.4 \pm 3.6$ & 27.9 & 1.4 & 27.1 & 2.2 & No \\
\hline Sydney, Australia & 423 & 14.9 & 36.6 & 48.5 & 49.6 & $58.5 \pm 11.9$ & $28.0 \pm 5.1$ & 12.5 & 12.8 & 29.8 & 8.5 & Yes \\
\hline Tartu, Estonia & 611 & 18.2 & 29.3 & 52.5 & 50.2 & $60.8 \pm 12.0$ & $28.4 \pm 5.2$ & 8.8 & 37.3 & 40.1 & 7.2 & Yes \\
\hline Tirana, Albania & 926 & 21.8 & 15.2 & 63.0 & 49.8 & $54.7 \pm 10.6$ & $28.1 \pm 4.7$ & 17.2 & 4.2 & 22.8 & 6.5 & No \\
\hline Uppsala, Sweden & 547 & 14.3 & 43.1 & 42.6 & 51.7 & $58.4 \pm 10.9$ & $27.0 \pm 4.4$ & 10.1 & 11.0 & 28.7 & 3.8 & Yes \\
\hline Vancouver, Canada & 821 & 13.9 & 38.4 & 47.7 & 41.7 & $55.8 \pm 11.5$ & $26.7 \pm 5.2$ & 8.5 & 12.8 & 20.2 & 7.1 & Yes \\
\hline Total & 23,623 & 19.0 & 21.1 & 59.8 & 47.5 & $55.1 \pm 10.8$ & $26.7 \pm 5.5$ & 31.7 & 10.8 & 26.2 & 8.1 & \\
\hline
\end{tabular}

BMI, body mass index; RS, Restricted spirometry; GNI, gross national income; CVD, cardiovascular disease; SD, standard deviation

Random effects meta-analyses were performed using, for each site, the odds ratios of CVD, diabetes and hypertension, in participants with restricted spirometry compared to those without restricted spirometry. Additionally, these analyses were stratified by: (1) sex and the adjusted sex-specific odds ratios were compared for males and females by a Z-score after log-transformation; and (2) high- versus low-/middleincome countries based on gross national income per capita, according to World Bank in 2013. Study sites that reported a low number of people with a specific comorbidity $(<20)$ or with singularity in the data (i.e. no one with both low FVC and that specific comorbidity) were excluded from the meta-analysis because these sites could not be fitted in the model. These sites were mentioned in detail in the legends of the meta-analyses.

Differences were considered to be significant if $\mathrm{p}$ was less than 0.05 . Heterogeneity across sites was estimated using the $\mathrm{I}^{2}$ statistic. $\mathrm{I}^{2}$ values of $0 \%, 25 \%, 50 \%$, and $75 \%$ were respectively considered as no, low, moderate, and high heterogeneity, respectively [31]. 
Target population database $(n=23834)$

Subjects aged 40-89 years with acceptable post bronchodilator spirometry and smoking history obtained

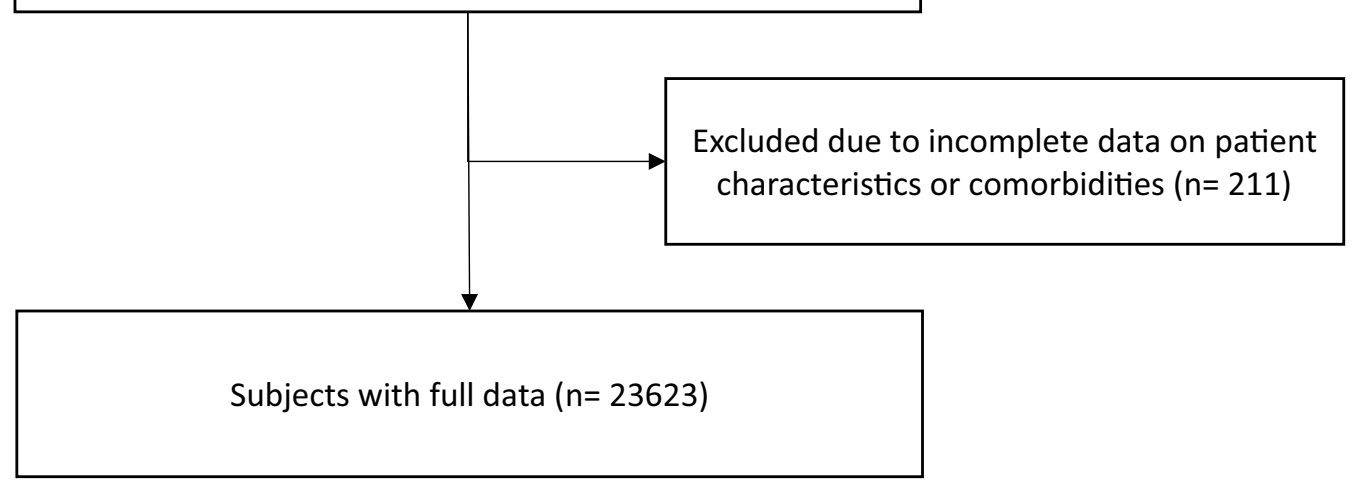

Fig. 1 Flow chart of data extraction

\section{Results}

\section{Study population characteristics}

From 23,834 participants aged 40-89 years, with an acceptable post-bronchodilator spirometry and smoking history, 23,623 participants had complete data with regard to subject characteristics and presence of comorbidities (Fig. 1). Fourteen out of 33 study sites (39\%) were located in countries with a high-income economy. Overall and per site baseline characteristics are shown in Table 1. Study participants had a mean age of $55.1 \pm 10.8$ years, were slightly overweight (BMI $26.7 \pm 5.5 \mathrm{~kg} / \mathrm{m}^{2}$ ), and approximately half of them were males (47.5\%). Most of them were never smokers, and one out of five were current smokers. Several sites in Africa and India had a high percentage of never smokers.

Thirty-two percent of the overall population had a restricted spirometry, with a high variation across sites. The highest prevalence of restricted spirometry was noted in Colombo (Sri Lanka) (81\%), but also in sites in Africa, India, the Philippines and Malaysia had strikingly high prevalence of restricted spirometry. Of notice, 12 of 17 sites with a restriction prevalence below $20 \%$ were

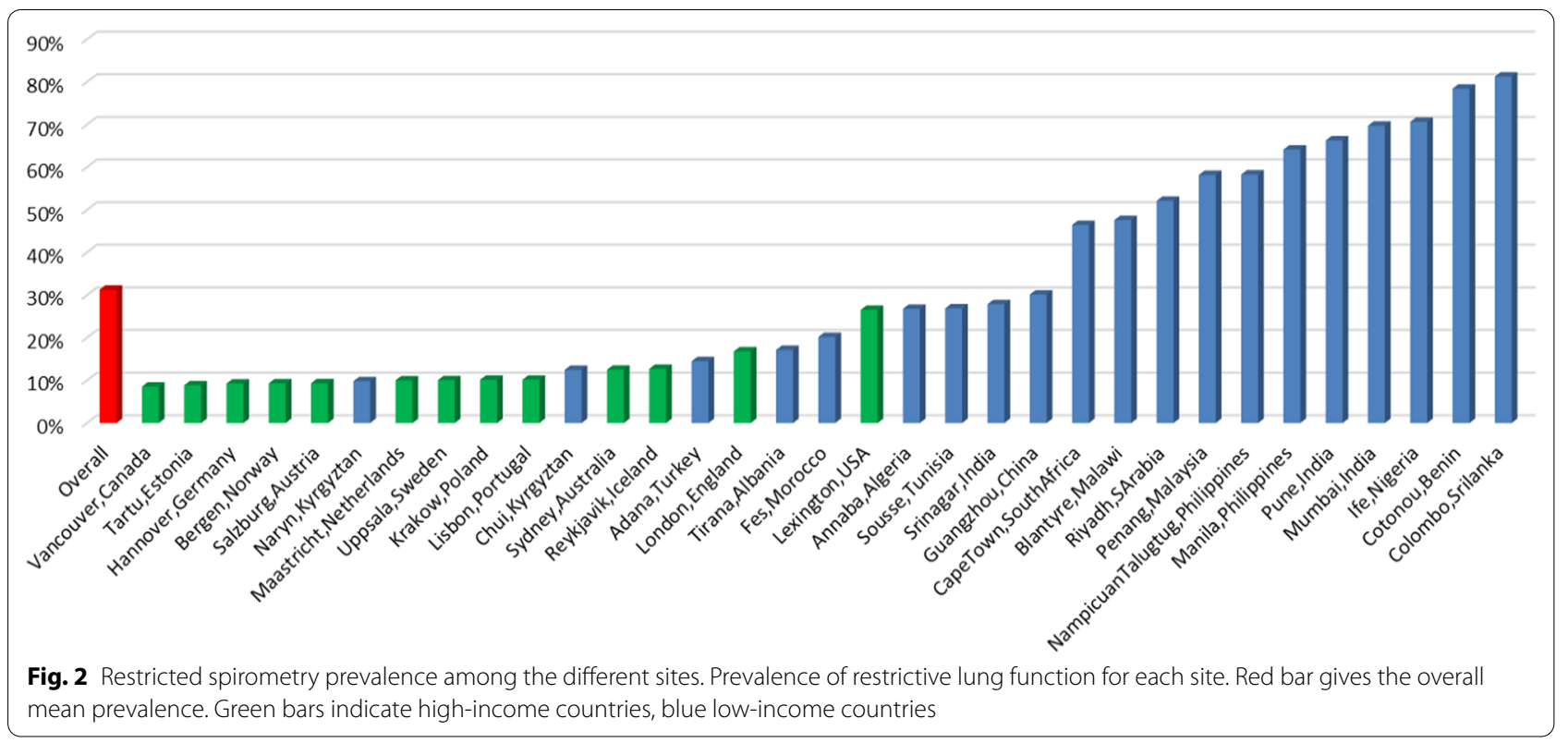


high income sites, compared to only 1 of the 16 sites with a restriction prevalence above $20 \%$ (Fig. 2).

\section{Prevalence of comorbidities}

The prevalence was $10.8 \%$ for CVD, $26.2 \%$ for hypertension and $8.1 \%$ for diabetes and, was $10.9 \%, 28.9 \%, 8.2 \%$ for females, and $10.7 \%, 23.2 \%, 7.8 \%$ for males (Table 1 ), respectively. These comorbidities were more prevalent with older age and increasing BMI. The prevalence of CVD increased with an increasing cigarette pack-years and decreased in participants with a higher level of education. Current smokers were less likely to report CVD, hypertension or diabetes. The highest prevalence of CVD was noted in Tartu (Estonia) (37.3\%), Krakow (Poland) (32.4\%) and Lexington (KY, USA) (29.3\%), whereas the lowest prevalence was reported in Ife (Nigeria) (0.2\%), Pune (India) (1.4\%) and Srinagar (India) (1.4\%). The prevalence of hypertension did not differ substantially across countries with exception of Ife in Nigeria (2.3\%), Pune in India (5.1\%), Krakow in Poland (42.0\%), Lexington, KY, in USA (49.1\%) and Tartu in Estonia (40.1\%). The reported prevalence of diabetes varied across sites, being lowest in
Ife (Nigeria) with $0.8 \%$ and highest in Riyad (Saudi Arabia) with $29.4 \%$.

\section{The association between restrictive lung function and comorbidities}

Overall, participants with restricted spirometry consistently more often reported CVD (OR 1.60, 95\% CI 1.37-1.86), diabetes (OR 1.98, 95\% CI 1.71-2.29) and hypertension (OR 1.53, 95\% CI 1.40-1.66) than those with unrestricted spirometry (Table 2). When considering sex-specific estimates, females with restricted spirometry more often reported hypertension, and diabetes, while men more often reported CVD. Regarding between-sites heterogeneity, an overall moderate heterogeneity $\left(I^{2} 47.6 \%\right.$; $\left.=0.015\right)$ was reported for $C V D$ and diabetes $\left(\mathrm{I}^{2} 47.7 ; \mathrm{p}=0.008\right)$. Non-significant low heterogeneity across sites was observed for hypertension $\left(\mathrm{I}^{2} 19.7 \% ; \mathrm{p}=0.164\right)$.

After adjusting for sex, age, BMI, smoking status, pack-years and education, the presence of restrictive lung function was still strongly associated with CVD (OR 1.54, 95\% CI 1.33-1.79), hypertension (OR

Table 2 Meta-analysis of the unadjusted and adjusted odds ratios for cardiovascular disease, diabetes and hypertension in participants with restricted spirometry

\begin{tabular}{|c|c|c|c|c|c|c|}
\hline \multicolumn{4}{|c|}{ Unadjusted } & \multicolumn{3}{|c|}{ Adjusted } \\
\hline & OR & $95 \% \mathrm{Cl}$ & $\begin{array}{l}\mathrm{I}^{2} \% \text { and } \mathrm{p} \text {-value for between } \\
\text { site heterogeneity }\end{array}$ & OR & $95 \% \mathrm{Cl}$ & $\begin{array}{l}\mathrm{I}^{2} \% \text { and } \mathrm{p} \text {-value } \\
\text { for between site } \\
\text { heterogeneity }\end{array}$ \\
\hline \multicolumn{7}{|c|}{ Cardiovascular disease } \\
\hline Male & 1.67 & $1.34-2.08$ & $\begin{array}{l}44 \% \\
p=0.013\end{array}$ & 1.77 & $1.33-2.36$ & $\begin{array}{l}64.6 \% \\
p<0.001\end{array}$ \\
\hline Female & 1.56 & $1.26-1.93$ & $\begin{array}{l}41.7 \% \\
p=0.015\end{array}$ & 1.52 & $1.20-1.93$ & $\begin{array}{l}43.2 \% \\
p=0.011\end{array}$ \\
\hline Overall & 1.60 & $1.37-1.86$ & $\begin{array}{l}47.6 \% \\
p=0.003\end{array}$ & 1.54 & $1.33-1.79$ & $\begin{array}{l}35.2 \% \\
p=0.038\end{array}$ \\
\hline \multicolumn{7}{|c|}{ Hypertension } \\
\hline Male & 1.49 & $1.30-1.69$ & $\begin{array}{l}29.4 \% \\
p=0.062\end{array}$ & 1.56 & $1.37-1.78$ & $\begin{array}{l}8.6 \% ; \\
p=0.329\end{array}$ \\
\hline Female & 1.6 & $1.42-1.79$ & $\begin{array}{l}18.4 \% \\
p=0.180\end{array}$ & 1.51 & $1.34-1.71$ & $\begin{array}{l}13 \% \\
p=0.260\end{array}$ \\
\hline Overall & 1.53 & $1.40-1.66$ & $\begin{array}{l}19.7 \% \\
p=0.164\end{array}$ & 1.50 & $1.39-1.63$ & $\begin{array}{l}0 \% ; \\
p=0.606\end{array}$ \\
\hline \multicolumn{7}{|l|}{ Diabetes } \\
\hline Male & 1.86 & $1.59-2.18$ & $\begin{array}{l}0 \% ; \\
p=0.682\end{array}$ & 1.95 & $1.64-2.33$ & $\begin{array}{l}0 \% ; \\
p=0.694\end{array}$ \\
\hline Female & 1.91 & $1.56-2.35$ & $\begin{array}{l}44.1 \% \\
p=0.021\end{array}$ & 1.76 & $1.45-2.14$ & $\begin{array}{l}26 \% \\
p=0.145\end{array}$ \\
\hline Overall & 1.98 & $1.71-2.29$ & $\begin{array}{l}44.7 \% \\
p=0.008\end{array}$ & 1.86 & $1.59-2.17$ & $\begin{array}{l}44.9 \% \\
p=0.008\end{array}$ \\
\hline
\end{tabular}

$\mathrm{I}^{2}$ values of $0 \%, 25 \%, 50 \%$, and $75 \%$ were respectively considered as no, low, moderate, and high heterogeneity. The following sites could not be included in the analysis due to a low number of participants reporting comorbidity or with singularity in the data: Blantyre (Malawi) for CVD, Cotonu (Benin) for diabetes, Guangzhou (China) for diabetes, Ife (Nigeria) for CVD, diabetes and hypertension, Mumbai (India) for CVD, Nampicuan Talugtug (Philippines) for diabetes, Naryn (Kyrgyztan) for diabetes, Penang (Malaysia) for CVD, Pune (India) for CVD and diabetes, Srinagar (India) for CVD and diabetes 


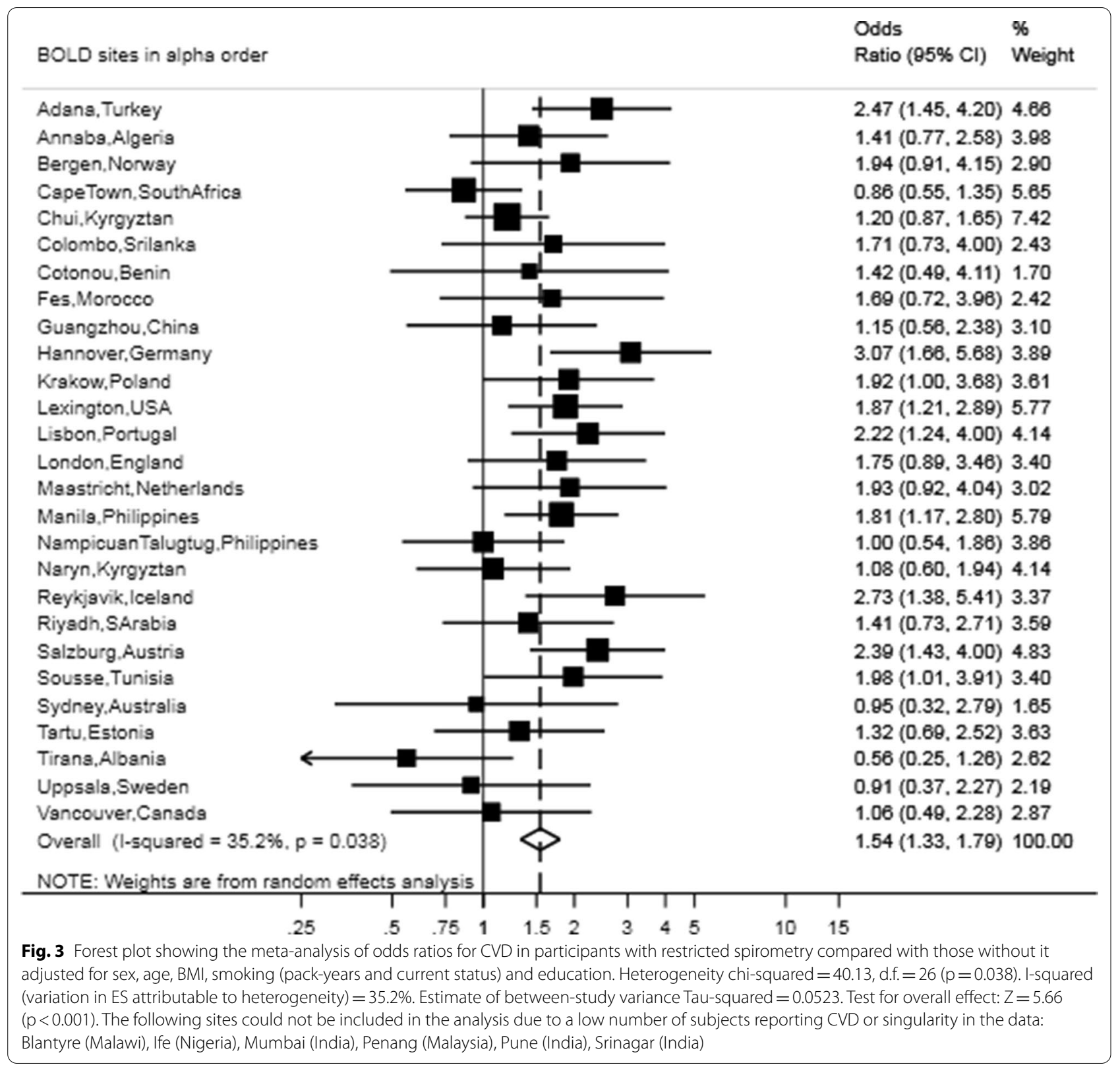

1.50, 95\% CI 1.39-1.63) and diabetes (OR 1.86, 95\% CI 1.59-2.17) (Figs. 3, 4, 5). The meta-analyses stratified by sex showed similar odds ratios as the joint analysis (Table 2).

Association of restricted spirometry with comorbidities stratified by low-/middle- and high-income countries and sex is presented in Table 3. In general, the association between the presence of restricted spirometry and comorbidities persisted in both high- and low-/middleincome countries.

\section{Discussion}

In this population-based study including 33 sites from 29 countries involving more than 23,000 individuals with high-quality post-bronchodilator spirometry, restricted spirometry was associated with the prevalence of selfreported diabetes, hypertension, and CVD. These associations were barely attenuated by age, sex, smoking, BMI and education. These findings were consistent across sites, regardless of gross national income. 


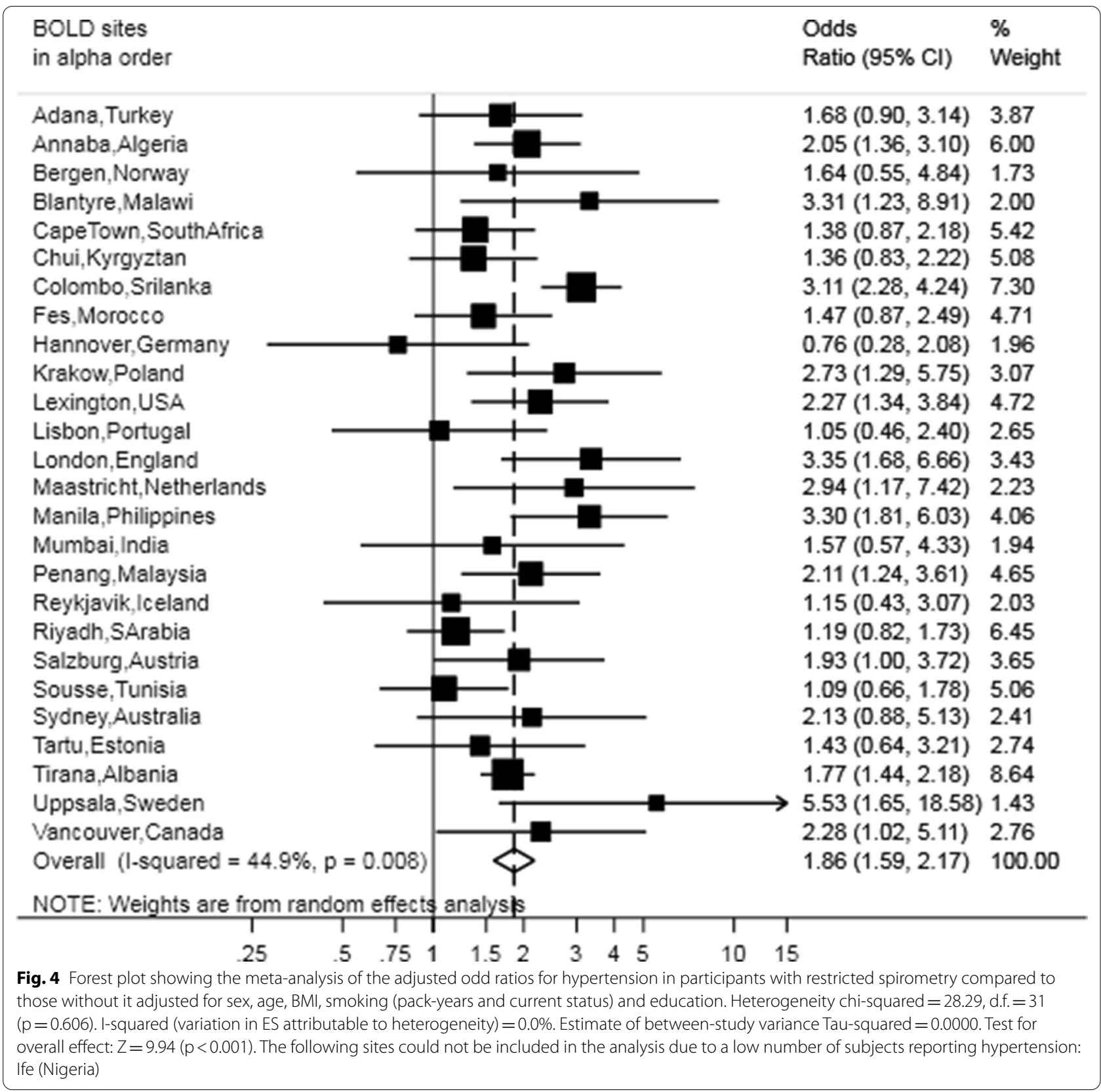

We found a high variation across sites in prevalence of restrictive spirometry, with higher prevalence in low-/middle-income countries (particularly Asian and African countries). We purposively used the NHANES III prediction equations for Caucasians for all sites [26, 32]. The use of locally derived reference equations from our study sample would prevent to reveal all environmental influences. Literature supports that differences in ethnicity have minor influence on lung development in relation to environment [5]. Use of race- or ethnicity-based predictive equations is controversial, and assumptions that observed variations in lung function are due to race or ethnicity should be avoided [33]. Rather, studies such as BOLD highlight the marked differences in developmental and environmental exposures across populations that affect lung growth and mature lung function. In the BOLD study, for example $15.4 \%$ of participants in Cape Town (South Africa) and $10.8 \%$ in Manila (Philippines) (reported prevalence of FVC below the lower limit of normal (LLN) $46.5 \%$ and $62.4 \%$, respectively) self-reported a history 


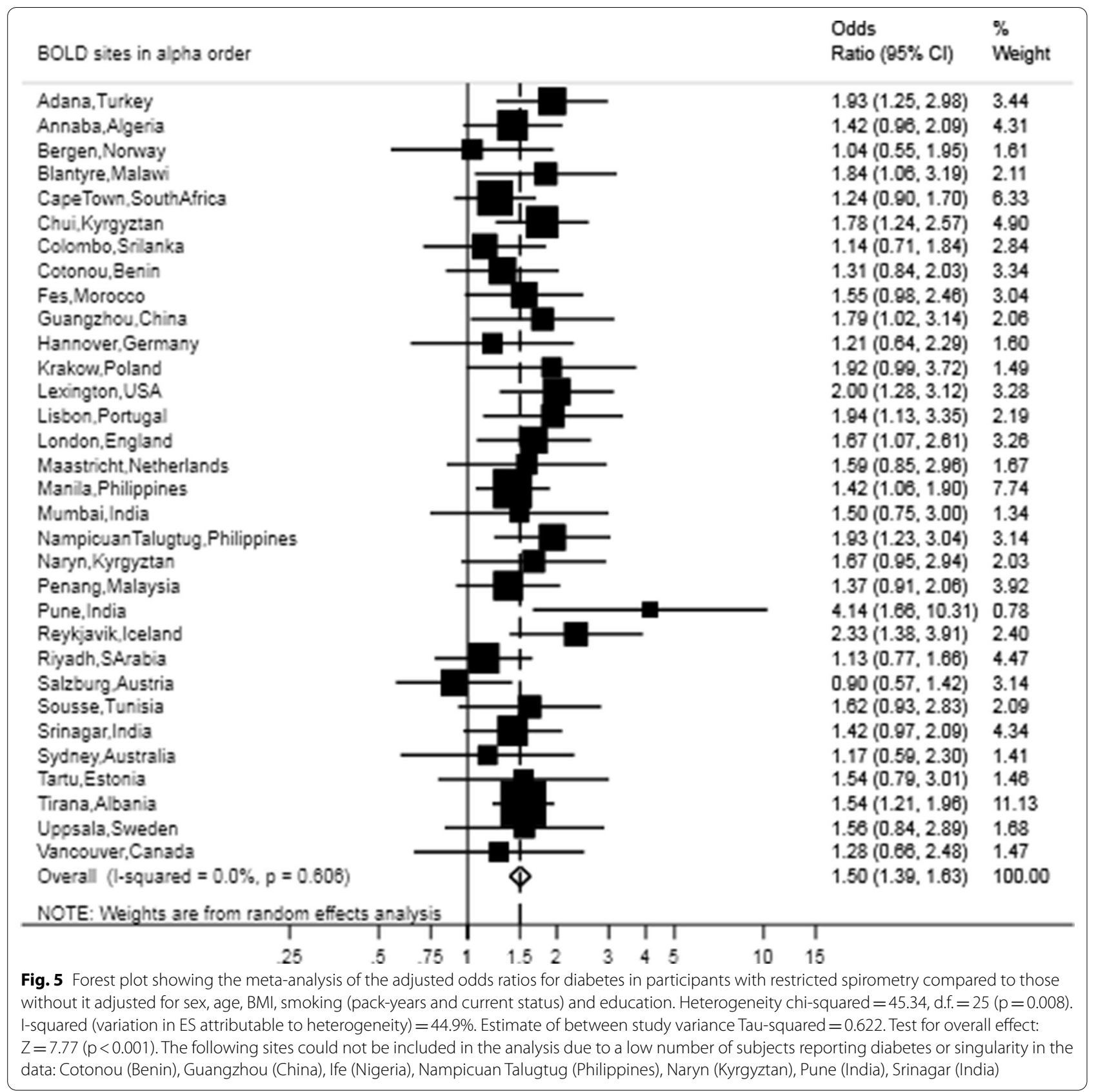

of tuberculosis [10,34], and the actual prevalence of tuberculosis in those regions may be higher.

In line with our results, several other population-based studies consistently reported the positive association between restrictive lung function and cardiovascular diseases [14, 35]. Lindberg et al. measured cardiovascular disease in subjects with restricted, obstructed and normal lung function. They reported a lower prevalence of CVD in restricted than in obstructed participants, but a higher prevalence in restricted than in healthy persons [14]. Eriksson et al. reported that heart disease among subjects with restrictive lung function was about three to six times more prevalent compared to those with normal spirometry. The proportion of hypertension in restrictive subjects was similar to that in subjects with Chronic obstructive pulmonary disease (COPD) stage 3 and 4 [35]. Previous research also demonstrated that the risk for experiencing a cardiovascular event in subjects with restricted lung function during 15-years follow-up was similar 


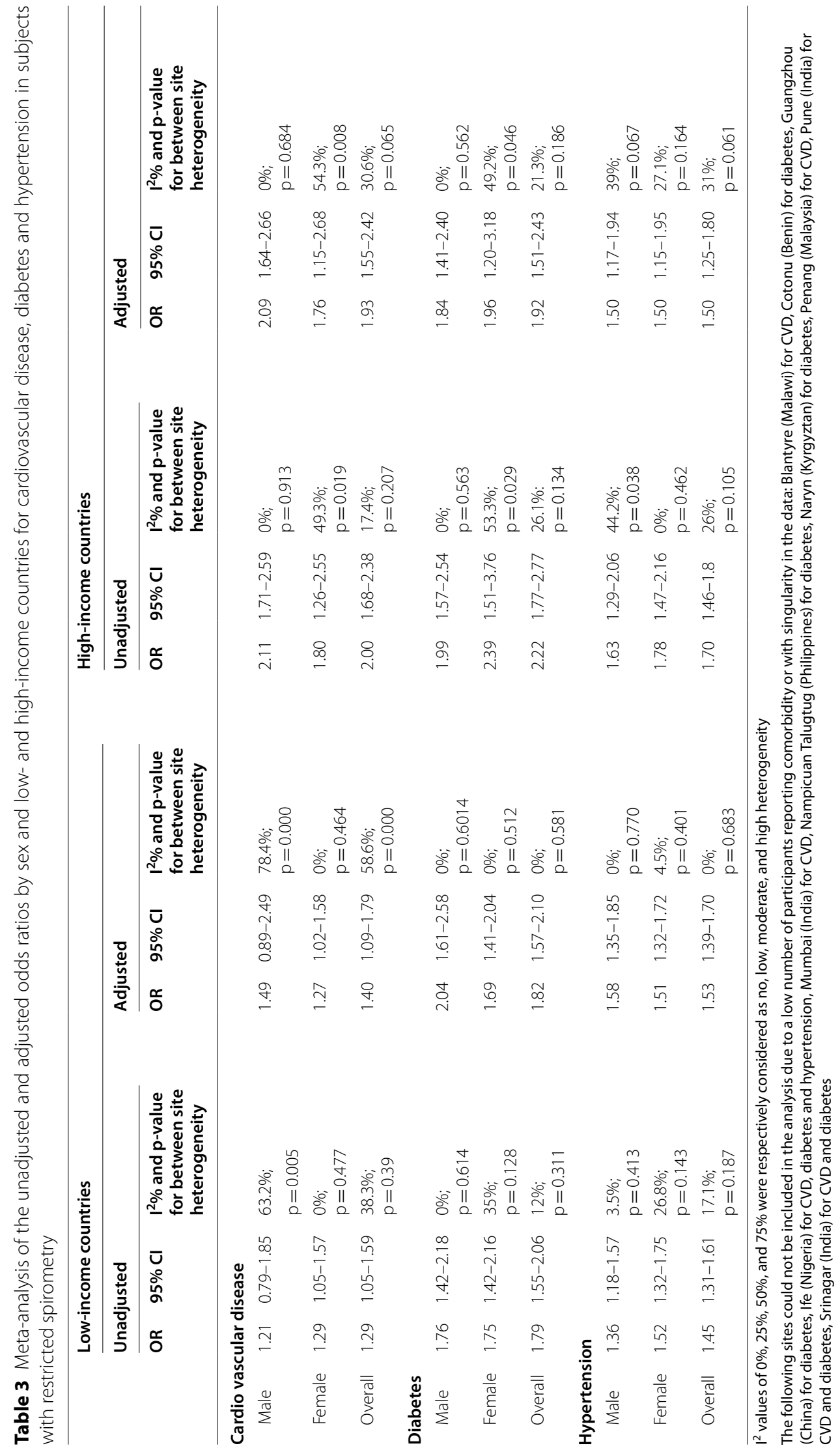


to subjects with moderate airflow limitation indicating COPD [12].

In the above studies, a restrictive spirometry pattern has been commonly described as a decreased FVC in combination with a normal or increased FEV1/FVC ratio, and then compared to an obstructive spirometry pattern independent of FVC. This likely ignores the potential coexistence of a restriction in vital capacity in subjects with obstructive lung function. More severe static hyperinflation related to severe airflow limitation might result in a decreased vital capacity, but this is uncommon in a population-based study. We previously showed that the association of CVD and hypertension with airflow limitation in this study population was largely explained by age and smoking habits and that the adjusted risk for diabetes was even lower in subjects with airflow limitation [36]. Here we aimed to focus on the association between low FVC and cardiometabolic comorbidities independent of the presence or absence of airflow limitation and showed a much stronger association for restrictive spirometry with cardiometabolic comorbidities compared to our previous findings related to obstructive spirometry. Hence, previous reported associations of cardiometabolic comorbidities with obstructive spirometry in population studies might be partly explained by coexistent restriction.

It has been suggested that poor nutritional status is a risk factor for impaired lung function $[37,38]$. In a longitudinal population study, Ubilla et al. reported that low $\mathrm{BMI}$ in adults associates with low $\mathrm{FEV}_{1}$ and FVC. In the present study, of the 10 countries with the lowest BMI, 8 had a restricted spirometry prevalence of over $40 \%$, which all were low-/middle- income countries. On the other hand, obesity has been associated with decreased vital capacity in several observational studies $[14,39,40]$. In this study, we observed lower FVC in countries with a high prevalence of obesity, like the United States of America. Also, significant association between restrictive lung function and diabetes has been shown [3, 41]. A potential explanation for the association between low FVC and the presence of diabetes could be through obesity and related insulin resistance. Nevertheless, even after adjustment for BMI, the adjusted odds ratio did not alter the significant association in the present study. In line with this, the presence of diabetes has been shown to be associated with a restrictive lung function pattern in a meta-analysis [42]. Furthermore, subclinical impairment of lung function was seen in children with type 1 diabetes mellitus and was associated with disease duration and the degree of metabolic control [43]. This might not surprise as the large vascular network and high collagen and elastin composition of the pulmonary system, is prone to microvascular damage and nonenzymatic glycation in diabetes.

There is increasing attention for the potential role of early life events and their role in lung function and other organ function development. Restricted lung function could be the result of suboptimal lung development, related to environmental influences in utero, during early childhood and adolescence. Prenatal foetus's exposure, thereafter childhood environmental exposure, respiratory infections and nutritional influences are potential contributing factors to suboptimal lung development. Agusti et al. described the abnormal lung development and suggested that lower lung function, might be related to suboptimal development of the other organs, which might relate to an earlier and higher prevalence of comorbidity [21, 44]. This is a potential explanation for the association seen in the current study between low lung function and the presence of comorbidities.

The stratified results for low-/middle- and highincome countries yielded comparable outcomes for hypertension and diabetes, although the associations between comorbidities and restricted spirometry were less strong in low-/middle-income countries. This could be related to the high proportion of subjects with restrictive lung function in low-/middle-income countries which could dilute the effect size. On the other hand, the effect of a lower socioeconomic status on underestimating the prevalence of non-communicable diseases has been reported to be more pronounced in countries with low-income economies compared to those with high-income economies [45].

In high income countries, in which the NHANES III reference equations might be more applicable, the main objective and outcome of this study, that restrictive lung function is strongly associated with cardiometabolic comorbidities is confirmed.

By its cross-sectional design, the current general population study describes the association between restricted spirometry and cardiometabolic comorbidity. The strictly standardized spirometry is one of the main strengths of the current study. Another strength of this study is that a great number of population-based samples worldwide, accounting for regional differences with regard to exposure [46] and potential ethnical and socioeconomical differences were investigated. Remarkably, the meta-analyses had low to moderate heterogeneity across study sites. Limitations of the current study include healthy participant bias and the self-reported nature of the comorbidity assessment. As discussed, we purposively used the same prediction equations for all countries as NHANES III [26]. 
The use of locally derived reference equations from our study sample would prevent to reveal all environmental influences.

\section{Conclusion}

In conclusion, the results of the international BOLD study show that on the population level, subjects with restricted spirometry are more often affected by CVD, hypertension and diabetes. Furthermore, this association is not attenuated by the presence of common risk factors, such as aging and smoking. These findings emphasize the urgent need to understand better the mechanisms underlying the association between impaired lung function and cardiometabolic disease, particularly in low-income countries where restrictive lung function is more prevalent and a shift from communicable diseases to non-communicable diseases is underway.

\begin{abstract}
Abbreviations
BMI: Body Mass Index; BOLD: Burden of Obstructive Lung Disease; Cl: Confidence Interval; COPD: Chronic Obstructive Pulmonary Disease; CVD: Cardiovascular disease; $F_{E V}$ : Forced expiratory volume in the first second; FVC: Forced vital capacity; LLN: Lower limit of normal; NHANES III: The Third National Health and Nutrition Examination Survey; OR: Odd ratio.

\section{Acknowledgements}

The authors thank the participants and field workers of this study for their time and cooperation, and the BOLD Coordinating Centre members not included in the author list for their technical and scientific support. BOLD wishes to acknowledge the contributions of Georg Harnoncourt of the ndd Corporation and Paul Enright for their assistance with spirometry training and quality control during the study.
\end{abstract}

\section{Authors' contributions}

MS, BL, PGJB, LEGWV contributed to conception and study design. KKO, FJJT, MS, WMV, PJGB, LEGWV analyzed the data. KKO, FJJT, WMV, PJGB, LEGWV interpreted the data. All authors contributed to drafting the article or revising it critically for important intellectual content and gave final approval of the version to be published. All authors take responsibility for the integrity of the data and accuracy of the data analysis. All authors read and approved the final manuscript.

\section{Funding}

Open access funding provided by University of Gothenburg. The BOLD Study was funded by a grant from The Wellcome Trust (085790/Z/08/Z), which supported the London, UK Co-ordinating Centre, and in part by unrestricted educational grants to the initial Co-ordinating Centre in Portland, OR, USA from Aventis, AstraZeneca, Boehringer-Ingelheim, Chiesi, GlaxoSmithKline, Merck, Novartis, Pfizer, Schering-Plough, Sepracor and the University of Kentucky (Lexington, KY). LEGWV received funding from Kamprad Family Foundation (ref. 20190024), Hjärt-lungfonden (nr. 20200150) and Swedish government and country council ALF Grant (ALFGBG-824371). None of the funding bodies had a role in the design of the study, collection, analyzes or interpretation of data, in the writing of the manuscript or in the decision to publish the results.

\section{Availability of data and materials}

The datasets used and analyzed during the current study are available from the corresponding author on reasonable request.

\section{Declarations}

Ethics approval and consent to participate

Approval was obtained from each local ethics committee, and written informed consent was obtained from each participant. Indian Institute of Environmental Medicine, Mumbai, India, approval IIEM/IEC/005/2004-05; Chest Research Foundation Independent Ethics Committee, KEM Hospital Research Centre, Pune, India, approval 19/6/2008, KEMHRCNSP/Dir.Off/EC/539 and KEMHRC ID No. 0931; Sher-I-Kashmir Institute of Medical Sciences, Srinagar, India, approval SIMS-1-31-IEC/2010-2557 (research protocol 6/2010); Philippine National Ethics Committee, Philippines approval 7/3/2008; University of Cape Town, Cape Town, South Africa, approval 152/2003; Kyrgyz National Centre of Cardiology and Internal Medicine, approval 01-7/49 of 6/2/2013; Obafemi Awolowo University Teaching Hospitals Complex, Ile-Ife, Nigeria, approval ERC/2011/01/04; Etablissement Hospitalier Specialise Universitaire de Medecine Physique et Readaptation de Seraidi, approval 13/S/M/2012; Comite National d'Ethique de la Recherche pour la Sante Humaine, approval 2013/11/373/L/CNERSH/SP; University Hospital Farhat Hached, Sousse, Tunisia, approval 24/4/2010; University of Tartu, Tartu, Estonia, approval 118/53; National Bioethics Committee, Reykjavik, Iceland, approval 04-080; Regional Committee for Medical and Health Research Ethics of Western Norway (REK Vest), Bergen, Norway, approval 098.05; Regional Ethical Review Board in Uppsala, Uppsala, Sweden, approval 2006/146; Bioethics Committee of the JagielIonian University Medical School, Krakow, Poland, approval KBET/36/B/2005;

Charing Cross Hospital, London, UK, approval 06/Q0411/97; Hannover Medical School, Hannover, Germany, approval 3804/2004; University of Kentucky, Lexington, Kentucky, approval 04-0714-F3R; Hospital Pulido Valente, Lisbon, Portugal, approval CE/25/07 (Estudo 21/07); Academic hospital of Maastricht (azM) and Maastricht University (UM), Maastricht, The Netherlands, approval MEC-062-084; Ethics Committee for the State of Salzburg, Salzburg, Austria, approval 556/10a; University of Sydney, Sydney, Australia, approval 12-2005/1/8641; University of British Columbia/Providence Health Care, approval P05-0061; Adana Valiligi Provincial Health Directorate, Adana, Turkey, approval 03-15-442; Guangzhou Institute of Respiratory Disease, Guangzhou, China, approval 2003-01; Philippine National Ethics Committee, Philippines, approval 9/8/2005; Ethics Review Committee of the Faculty of Medicine of the University of Kelaniya, Sri Lanka (FWA00013225), approval P5/01/2011; National Bioethics Committee, Ministry of Health, Republic of Albania, approval 18 (10/6/2011); National Guard-Health Affairs, King Abdulaziz Medical City, Institutional Review Board, approval IRBC/038/11 (5/3/2011); Joint Penang Independent Ethics Committee, approval JPEC 12-12-0202 (11/12/2012).

\section{Consent for publication}

Not applicable.

\section{Competing interests}

FMEF reports grants and personal fees from AstraZeneca, personal fees and non-financial support from Boehringer Ingelheim, personal fees from Chiesi, personal fees from GlaxoSmithKline, personal fees from Novartis, non-financial support from TEVA, outside the submitted work. KKO, FJJT, BL, PGJB, EFMW, WMV, AFSA, MS, LEGWV report no competing interests.

\section{Author details}

${ }^{1}$ COPD Center, Department of Respiratory Medicine and Allergology, Sahlgrenska University Hospital, Gothenburg, Sweden. ${ }^{2}$ Department of Internal Medicine and Clinical Nutrition, Institute of Medicine, Sahlgrenska Academy, University of Gothenburg, Gothenburg, Sweden. ${ }^{3} \mathrm{CIRO}$, Centre of Expertise for Chronic Organ Failure, Horn, the Netherlands. ${ }^{4}$ Department of Respiratory Medicine, AZ Sint-Lucas, Gent, Belgium. ${ }^{5}$ Department of Respiratory Medicine, MUMC+, Maastricht University Medical Centre, Maastricht, the Netherlands. ${ }^{6}$ Department of Pneumology, Paracelsus Medical University, Salzburg, Austria. ${ }^{7}$ Kaiser Permanente Center for Health Research, Portland, OR, USA. ${ }^{8}$ Department of Pulmonary Medicine, Kepler-University-Hospital, Linz, Austria. ${ }^{9}$ Faculty of Medicine, Johannes-Kepler-University, Linz, Austria. ${ }^{10}$ National Heart and Lung Institute, Imperial College London, London, UK. ${ }^{11}$ Ludwig Boltzman Institute for Lung Health, Vienna, Austria. 
Received: 9 March 2021 Accepted: 24 January 2022

Published online: 17 February 2022

\section{References}

1. Stansbury RC, Mannino DM. Diseases associated with restrictive lung function impairment. In: Bellia V, Antonelli Incalzi R, editors. Respiratory diseases in the elderly; 2009. p. 366.

2. Aaron SD, Dales RE, Cardinal P. How accurate is spirometry at predicting restrictive pulmonary impairment? Chest. 1999;115:869-73.

3. Guerra S, Carsin AE, Keidel D, Sunyer J, Leynaert B, Janson C, Jarvis D, Stolz D, Rothe T, Pons M, Turk A, Anto JM, Probst-Hensch N. Health-related quality of life and risk factors associated with spirometric restriction. Eur Respir J. 2017;49:1602096.

4. Gupta RP, Strachan DP. Ventilatory function as a predictor of mortality in lifelong non-smokers: evidence from large British cohort studies. BMJ Open. 2017;7:e015381.

5. Burney PG, Hooper RL. The use of ethnically specific norms for ventilatory function in African-American and white populations. Int J Epidemiol. 2012;41:782-90.

6. Godfrey MS, Jankowich MD. The vital capacity is vital: epidemiology and clinical significance of the restrictive spirometry pattern. Chest. 2016:149:238-51.

7. Sood A, Petersen H, Qualls C, Meek PM, Vazquez-Guillamet R, Celli BR, Tesfaigzi Y. Spirometric variability in smokers: transitions in COPD diagnosis in a five-year longitudinal study. Respir Res. 2016;17:147.

8. Lederer DJ, Enright PL, Kawut SM, Hoffman EA, Hunninghake G, van Beek EJ, Austin JH, Jiang R, Lovasi GS, Barr RG. Cigarette smoking is associated with subclinical parenchymal lung disease: the Multi-Ethnic Study of Atherosclerosis (MESA)-lung study. Am J Respir Crit Care Med. 2009;180:407-14.

9. Backman H, Eriksson B, Hedman L, Stridsman C, Jansson S-A, Sovijärvi A, Lindberg A, Rönmark E, Lundbäck B. Restrictive spirometric pattern in the general adult population: methods of defining the condition and consequences on prevalence. Respir Med. 2016;120:116-23.

10. Amaral AF, Coton S, Kato B, Tan WC, Studnicka M, Janson C, Gislason T, Mannino D, Bateman ED, Buist S, Burney PG, Group BCR. Tuberculosis associates with both airflow obstruction and low lung function: BOLD results. Eur Respir J. 2015;46:1104-12.

11. Gordon SB, Bruce NG, Grigg J, Hibberd PL, Kurmi OP, Lam KB, Mortimer K, Asante KP, Balakrishnan K, Balmes J, Bar-Zeev N, Bates MN, Breysse PN, Buist S, Chen Z, Havens D, Jack D, Jindal S, Kan H, Mehta S, Moschovis P, Naeher L, Patel A, Perez-Padilla R, Pope D, Rylance J, Semple S, Martin WJ 2nd. Respiratory risks from household air pollution in low and middle income countries. Lancet Respir Med. 2014;2:823-60.

12. Johnston AK, Mannino DM, Hagan GW, Davis KJ, Kiri VA. Relationship between lung function impairment and incidence or recurrence of cardiovascular events in a middle-aged cohort. Thorax. 2008;63:599-605.

13. Mannino DM, Thorn D, Swensen A, Holguin F. Prevalence and outcomes of diabetes, hypertension and cardiovascular disease in COPD. Eur Respir J. 2008;32:962-9.

14. Lindberg A, Larsson L-G, Rönmark E, Lundbäck B. Co-morbidity in mildto-moderate COPD: comparison to normal and restrictive lung function. COPD J Chronic Obstructive Pulm Dis. 2011;8:421-8.

15. Schroeder EB, Welch VL, Couper D, Nieto FJ, Liao D, Rosamond WD, Heiss G. Lung function and incident coronary heart disease: the Atherosclerosis Risk in Communities Study. Am J Epidemiol. 2003;158:1171-81.

16. Griffith KA, Sherrill DL, Siegel EM, Manolio TA, Bonekat HW, Enright PL. Predictors of loss of lung function in the elderly: the Cardiovascular Health Study. Am J Respir Crit Care Med. 2001;163:61-8.

17. Duprez DA, Hearst MO, Lutsey PL, Herrington DM, Ouyang P, Barr RG, Bluemke DA, McAllister D, Carr JJ, Jacobs DR. Associations among lung function, arterial elasticity, and circulating endothelial and inflammation markers. Hypertension. 2013;61:542-8.

18. Amaral AF, Patel J, Gnatiuc L, Jones M, Burney PG. Association of pulse wave velocity with total lung capacity: a cross-sectional analysis of the BOLD London study. Respir Med. 2015;109:1569-75.

19. McKeever TM, Weston PJ, Hubbard R, Fogarty A. Lung function and glucose metabolism: an analysis of data from the third national health and nutrition examination survey. Am J Epidemiol. 2005;161:546-56.
20. Brunner EJ, Shipley MJ, Witte DR, Singh-Manoux A, Britton AR, Tabak AG, McEniery CM, Wilkinson IB, Kivimaki M. Arterial stiffness, physical function, and functional limitation. Hypertension. 2011;57:1003-9.

21. Agusti A, Noell G, Brugada J, Faner R. Lung function in early adulthood and health in later life: a transgenerational cohort analysis. Lancet Respir Med. 2017:5:935-45.

22. Buist AS, Vollmer WM, Sullivan SD, Weiss KB, Lee TA, Menezes AM, Crapo RO, Jensen RL, Burney PG. The Burden of Obstructive Lung Disease Initiative (BOLD): rationale and design. COPD. 2005;2:277-83.

23. Perez-Padilla R, Vazquez-Garcia JC, Marquez MN, Jardim JR, Pertuze J, Lisboa C, Muino A, Lopez MV, Talamo C, de Oca MM, Valdivia G, Menezes AM. The long-term stability of portable spirometers used in a multinational study of the prevalence of chronic obstructive pulmonary disease. Respir Care. 2006;51:1167-71.

24. Miller MR, Hankinson J, Brusasco V, Burgos F, Casaburi R, Coates A, Crapo R, Enright P, van der Grinten CPM, Gustafsson P, Jensen R, Johnson DC, MacIntyre N, McKay R, Navajas D, Pedersen OF, Pellegrino R, Viegi G, Wanger J. Standardisation of spirometry. Eur Respir J. 2005;26:319-38.

25. Hankinson JL, Odencrantz JR, Fedan KB. Spirometric reference values from a sample of the general U.S. population. Am J Resp Crit Care Med. 1999;159:179-87.

26. Centers for Disease Control and Prevention. National Center for Health Statistics. The Third National Health and Nutrition Examination Survey (NHANES III) (cited 2020-09-23). https://wwwn.cdc.gov/nchs/nhanes/ nhanes3/Default.aspx.

27. Jousilahti P, Vartiainen E, Tuomilehto J, Puska P. Sex, age, cardiovascular risk factors, and coronary heart disease. A prospective follow-up study of 14786 middle-aged men and women in Finland. Circulation. 1999;99:1165-72.

28. Falkstedt D, Hemmingsson T. Educational level and coronary heart disease: a study of potential confounding from factors in childhood and adolescence based on the Swedish 1969 conscription cohort. Ann Epidemiol. 2011;21:336-42.

29. Bogers RP, Bemelmans WE, Hoogenveen RT, et al. Association of overweight with increased risk of coronary heart disease partly independent of blood pressure and cholesterol levels: a meta-analysis of 21 cohort studies including more than 300000 persons. Arch Intern Med. 2007;167:1720-8

30. Lubin JH, Couper D, Lutsey PL, Woodward M, Yatsuya H, Huxley RR. Risk of cardiovascular disease from cumulative cigarette use and the impact of smoking intensity. Epidemiology. 2016;27:395-404.

31. Higgins JPT, Thompson SG, Deeks JJ, Altman DG. Measuring inconsistency in meta-analyses. BMJ : British Medical Journal. 2003;327:557-60.

32. Statistics NCfH. National Health and Nutrition Examination Survey (NHANES III). CDC/National Center for Health Statistics; 1988-1994.

33. Braun L. Breathing race into the machine: the surprising career of the spirometer from plantation to genetics. Minneapolis: University of Minnesota Press; 2014.

34. Buist AS, McBurnie MA, Vollmer WM, Gillespie S, Burney P, Mannino DM, Menezes AM, Sullivan SD, Lee TA, Weiss KB. International variation in the prevalence of COPD (the BOLD Study): a population-based prevalence study. Lancet. 2007;370:741-50.

35. Eriksson B, Lindberg A, Müllerova H, Rönmark E, Lundbäck B. Association of heart diseases with COPD and restrictive lung function-results from a population survey. Respir Med. 2013;107:98-106.

36. Triest FJ, Studnicka M, Franssen FM, Vollmer WM, Lamprecht B, Wouters EF, Burney PG, Vanfleteren LE. Airflow obstruction and cardio-metabolic comorbidities. COPD J Chronic Obstructive Pulm Dis. 2019;16:109-17.

37. Salvi SS, Barnes PJ. Chronic obstructive pulmonary disease in non-smokers. Lancet. 2009;374:733-43.

38. Ubilla C, Bustos P, Amigo H, Oyarzun M, Rona RJ. Nutritional status, especially body mass index, from birth to adulthood and lung function in young adulthood. Ann Hum Biol. 2008;35:322-33.

39. Wu T, Brigham E, Brown T, McCormack M. Metabolic Syndrome Modifies the Association of Overweight/Obesity and Impaired Spirometry. A65 Obesity: American Thoracic Society; 2019. p. A2228-A2228.

40. Soriano JB, Miravitlles M, García-Río F, Muñoz L, Sánchez G, Sobradillo $\checkmark$, Durán E, Guerrero D, Ancochea J. Spirometrically-defined restrictive ventilatory defect: population variability and individual determinants. Prim Care Respir J. 2012;21:187-93. 
41. Klein OL, Krishnan JA, Glick S, Smith LJ. Systematic review of the association between lung function and Type2 diabetes mellitus. Diabet Med. 2010;27:977-87.

42. van den Borst B, Gosker HR, Zeegers MP, Schols AM. Pulmonary function in diabetes: a metaanalysis. Chest. 2010;138:393-406.

43. Anık A, Anık A, Uysal P. Assessment of pulmonary function by impulse oscillometry and spirometry in children with type 1 diabetes mellitus. Pediatr Pulmonol. 2020;55:3517.

44. Agusti A, Faner R. Lung function trajectories in health and disease. Lancet Resp Med. 2019;7:358.

45. Vellakkal S, Millett C, Basu S, Khan Z, Aitsi-Selmi A, Stuckler D, Ebrahim S. Are estimates of socioeconomic inequalities in chronic disease artefactually narrowed by self-reported measures of prevalence in low-income and middle-income countries? Findings from the WHO-SAGE survey. J Epidemiol Commun Health. 2015;69:218-25.

46. Rappaport SM. Implications of the exposome for exposure science. J Expos Sci Environ Epidemiol. 2011;21:5-9.

\section{Publisher's Note}

Springer Nature remains neutral with regard to jurisdictional claims in published maps and institutional affiliations.

- fast, convenient online submission

- thorough peer review by experienced researchers in your field

- rapid publication on acceptance

- support for research data, including large and complex data types

- gold Open Access which fosters wider collaboration and increased citations

- maximum visibility for your research: over $100 \mathrm{M}$ website views per year

At BMC, research is always in progress.

Learn more biomedcentral.com/submissions 